\title{
Weight Loss Is Still an Essential Intervention in Obesity and its Complications: A Review
}

\author{
Jianzhong Xiao and Wenying Yang \\ China-Japan Friendship Hospital, Beijing 100029, China \\ Correspondence should be addressed to Wenying Yang, ywy_1010@yahoo.com.cn
}

Received 27 February 2012; Accepted 1 May 2012

Academic Editor: Nomelí P. Núñez

Copyright () 2012 J. Xiao and W. Yang. This is an open access article distributed under the Creative Commons Attribution License, which permits unrestricted use, distribution, and reproduction in any medium, provided the original work is properly cited.

The prevalence of obesity is more than $20 \%$ in many developed countries and it increases in developing countries. Obesity is associated with metabolic disorders, cardiovascular diseases, pulmonary diseases, digestive diseases, and cancers. Although other specific treatments for these complications exist, weight loss is still an essential intervention in obesity and its complications. Therapeutic life change, behavior modification, pharmacotherapy, and surgery are major approaches to weight loss. In addition, medicine used in diabetes such as Glucagon-like peptide-1 analogues may be a new type of medicine for obesity, at least for those obese patients with diabetes.

\section{Introduction}

In 2005 the International Association for the Study of Obesity reported that the prevalence of obesity, defined by BMI $\geq 30 \mathrm{~kg} / \mathrm{m}^{2}$ is more than $20 \%$ in many European countries [1]. Future obesity for adults in the United States was projected on the basis of National Health and Nutrition Examination Study. By 2030, 86.3\% American adults will be overweight or obese; $51.1 \%$ of them will be obese. Total health-care costs attributable to obesity/overweight would double every decade to 2030 , accounting for $16-18 \%$ of total US health-care costs [2]. In China, a fast developing country, the prevalence of overweight and obesity also increased in the last two decades. The prevalence of overweight and obesity in 2008 in Chinese population aged 20 years or older reached $24.9 \%, 4.9 \%$ in women and $30.8 \%$ and $6.0 \%$ in men, respectively [3]. Timely and effective development and implementation of corrective approaches are needed to avoid the catastrophic health and social consequences.

\section{Obesity and Chronic Diseases}

Obesity is associated with a cluster of metabolic risk factors for coronary heart disease (CHD), known as metabolic syndrome. Abdominal obesity is an essential component of this syndrome, other components include impaired glucose regulation and type 2 diabetes mellitus; hypertriglyceridemia and/or low serum HDL-cholesterol levels; hypertension. In addition, increased serum levels of C-reactive protein; apolipoprotein B; small, dense LDL particles are also associated with abdominal obesity $[4,5]$. The epidemic of obesity is accompanied by the increase of these metabolic risk factors. The drastic increase in the prevalence of obesity has played an important role in the spread of diabetes not only in the United States $[6,7]$, but also in China. The prevalence of diabetes increases from $12.8 \%$ in those with a BMI of 25.0 to $29.9 \mathrm{~kg} / \mathrm{m}^{2}$ to $18.5 \%$ in those with a BMI greater than $30 \mathrm{~kg} / \mathrm{m}^{2}$. This increase even occurs in rather lean population in Chinese, that is, the prevalence of diabetes increased from $4.5 \%$ in those with a BMI $<18.5 \mathrm{~kg} / \mathrm{m}^{2}$ to $7.6 \%$ in those with a BMI of 18.5 to $24.9 \mathrm{~kg} / \mathrm{m}^{2}$ [8]. The association of hypertension and obesity has been described elsewhere [3, 912]. Consequently, the increase of BMI is associated with the increased cardiovascular diseases (CVD). For instance, the average BMI in patients with stroke is $25.5 \mathrm{~kg} / \mathrm{m}^{2}$, compared with $23.7 \mathrm{~kg} / \mathrm{m}^{2}$ in those without CVD in Chinese [3]. The risk of fatal and nonfatal myocardial infarction and ischemic stroke increases consistently with increasing BMI in other population $[13,14]$. 
Obesity is also complicated with pulmonary diseases such as obesity hypoventilation syndrome [15]. The Pickwickian syndrome is a severe form of the obesity-hypoventilation syndrome, involveing extreme obesity, irregular breathing, somnolence, cyanosis, secondary polycythemia, and right ventricular dysfunction.

Moreover, obesity is associated with a few digestive diseases. The risk of symptomatic gallstones increases linearly with BMI $[16,17]$. Obesity is associated with nonalcoholic fatty liver disease (NAFLD) that encompasses a spectrum ranging from simple steatosis to nonalcoholic steatohepatitis (NASH), fibrosis, and cirrhosis. Most of the available data suggests that steatosis affects approximately 75\%, steatohepatitis approximately $20 \%$, and cirrhosis approximately $2 \%$ of obese patients [18-20].

Overweight and obesity also increase the risk of cancer. A prospective study in more than 900,000 US adults [21], shows overweight and obesity could account for $14 \%$ of all deaths from cancer in men and $20 \%$ of deaths in women. A meta-analysis of 282,137 incident cases [22], demonstrated that in men, a $5 \mathrm{~kg} / \mathrm{m}^{2}$ increase in BMI was strongly associated with oesophageal adenocarcinoma and with thyroid, colon, and renal cancers. In women, strong associations between a $5 \mathrm{~kg} / \mathrm{m}^{2}$ increase in BMI and endometrial, gallbladder, esophageal adenocarcinoma, and renal cancers were recorded. Associations were stronger in men than in women for colon cancer. A stronger association in Asia-Pacific populations between increased BMI and premenopausal and postmenopausal breast cancers was recorded. Moreover, the risk of osteoarthritis of weightbearing joints is increased in overweight and obese persons and the knees were most often involved [23].

Compared with general obesity, abdominal obesity seemed to be more harmful than general obesity. The risk of diabetes increases with increases in abdominal fat mass, waist circumference, or waist-to-hip circumference ratio independent of BMI value $[24,25]$. Excess body fat deposited viscerally rather than elsewhere in the body is associated with higher risk for hypertension [26]. Abdominal fat mass is a risk factor for stroke independent of BMI, but not independent of diabetes, smoking, and hypertension [27].

\section{Mechanism Underlying Chronic Complications and Intervention in Obesity}

Although a great progress has been achieved in the study of mechanism underlying chronic complications in obesity, we are yet to clarify the specific mechanism. Insulin resistance is hypothesized to be the common underlying pathogenic mechanism of metabolic syndrome [28]. The ectopic accumulation of triglycerides in nonadipose tissue may be involved in the pathogenesis of insulin resistance [29]. However, according to data obtained from nondiabetic subjects in the Framingham Offspring Study, insulin resistance might not be the only precedent condition in metabolic syndrome, other independent physiologic process may be involved [30]. For instance, IKK $\beta / \mathrm{NF}-\kappa \mathrm{B}$ in the mediobasal hypothalamus - in particular in the hypothalamic POMC neurons may represent a primary pathogenic link between obesity and hypertension [31].

\section{Weight Loss: An Essential Intervention for Obesity Complicated with Chronic Diseases}

Weight loss has been proved to be an essential for the prevention, and treatment for obesity-related chronic diseases [22]. Sustained modest weight loss among obese persons would yield substantial benefit, reducing the lost number of years of life with hypertension, hypercholesterolemia, type 2 diabetes and the expected lifetime incidence of CHD and stroke [32, 33].

Modest weight loss over short-term (6 weeks) and longer-term (6-12 months) periods is associated with reduction in subsequent cardiovascular mortality for the following 4-5 years even in those with preexisting cardiovascular disease [34]. In morbidly obese subjects, bariatric surgery effectively induces weight loss and improvement in sleepdisordered breathing severity and symptoms [35]. Weight loss program also reported to have resulted in a highly significant improvement in symptoms in overweight patients with knee osteoarthritis [23]. Weight loss may not be a desirable for patients with cancer, however, it improved quality of life in breast cancer survivors [36]. Systematically review of 78 randomized trials has shown that lifestyleinduced weight loss was safe intervention for NAFLD, and that a weight loss $\geqslant 7 \%$ improved histological disease activity, but was achieved by $<50 \%$ patients [37].

Nevertheless, we should be aware of the side effect of weight loss. The risk of gallstones increases during weight loss, particularly when weight loss is rapid [38]. This increased risk is related to increased bile cholesterol supersaturation, enhanced cholesterol crystal nucleation, and decreased gallbladder contractility [39]. In a small 6month study, asymptomatic gallstones developed in 6/11 of subjects following the lower fat diet, but in none with the higher fat regimen [40]. A daily dose of $500 \mathrm{mg}$ of ursodeoxycholic acid for 6 months is effective prophylaxis for gallstone formation following gastric restrictive procedures [41].

\section{Approaches to Weight Loss}

Currently available weight-loss treatments include dietary intervention, increased physical activity, behavior modification, pharmacotherapy, and surgery. In China, acupuncture has been applied in the treatment of obesity, but no welldesigned clinical trial has been reported.

5.1. Dietary Intervention. Negative energy balance is more readily achieved by decreasing food intake than by increasing physical activity for most obese people. Many obese persons can achieve short-term weight loss by diet alone, but successful long-term weight maintenance is much more difficult. However, dietary intervention is still considered as the cornerstone of weight-loss therapy. Weight-loss diets 
can be classified according to their energy content. Lowcalorie diets (LCDs) contain 800 to $1500 \mathrm{kcal} /$ day and are consumed as liquid formula, nutritional bars, conventional food, or a combination of these items. Very-low-calorie diets (VLCDs) contain less than $800 \mathrm{kcal} /$ day and are generally high in protein $(70-100 \mathrm{~g} /$ day $)$ and low in fat $(<15 \mathrm{~g} /$ day $)$. The NIH guidelines recommend a more aggressive energy deficit of 500 to $1000 \mathrm{kcal} /$ day for persons with more severe obesity (BMI $\geq 35.0 \mathrm{~kg} / \mathrm{m}^{2}$ ). Individuals intended to reduce body weight should continue to be advised on regularly self-monitoring of energy intake and expenditure as well as creating a consistent daily energy deficit [42]. Low-fat diets have traditionally been prescribed for weight loss because such diets facilitate energy restriction, due to their low energy density. Low-carbohydrate diets have been evaluated as a potential therapy for obesity in RCTs. The mechanism responsible for the decrease in body weight associated with a low-carbohydrate diet can be completely explained by a decrease in total energy intake [43].

5.2. Physical Activity. There is a profound increase in energy expenditure during exercise. However, moderate endurance exercise, such as brisk walking for 45 to 60 minutes, 4 times a week, usually induces only minor weight loss in 1 year. Although exercise alone is not an effective strategy for inducing initial weight loss, increasing physical activity is an important component of successful long-term weight management. Fat-free mass (FFM) represents a key determinant of the magnitude of resting metabolic rate (RMR), which follows a decrease in lean tissue could hinder the progress of weight loss. Exercise training promotes a favorable change in body composition for weight loss [44]. Weight-loss maintenance requires expending approximately $2500 \mathrm{kcal} / \mathrm{wk}$ during exercise $[45,46]$. This level of energy expenditure can be accomplished through vigorous activity (aerobics, cycling, or jogging) for approximately $30 \mathrm{~min} /$ day or more moderate activity for 60 to $75 \mathrm{~min} /$ day.

5.3. Behavior Modification. Behavior modification for the treatment of obesity is perhaps the most important but difficult approach. It usually involves multiple strategies to modify eating and activity habits [47]. These strategies include: eating stimulus control, self-monitoring, problemsolving skills, cognitive restructuring, social support, and relapse prevention. Treatment by an enhanced brief lifestyle counseling (including medications) in primary care results in about a $4.6 \mathrm{~kg}$ in 2-year trials [47].

5.4. Pharmacotherapy. Conventional obesity therapy is associated with a high rate of relapse. Pharmacotherapy becomes a key method for the treatment of obesity. Unfortunately, Orlistat is only available medicine for long-term therapy, but the efficacy is limited [48, 49]. Pharmacotherapy alone is less successful than being part of a comprehensive weight-loss program that includes diet, exercise, and behavior modification [50]. Benzphetamine $\mathrm{HCl}$, phendimetrazine tartrate, phentermine, diethylpropion hydrochloride, mazindol, and orlistat are the drugs currently approved by the US Food and Drug Administration for the treatment of obesity. All currently approved weight-loss drugs act as anorexiants, with the exception of orlistat. Anorexiants affect the monoamine system in the hypothalamus and thereby enhance satiety. In the last several years, fenfluramine, phenylpropanolamine, sibutramine, and dexfenfluramine were withdrawn from the market because of the increased incidence of either valvular heart disease or cardiovascular diseases/stroke associated with their use $[51,52]$. All anorexiant drugs, except mazin$\mathrm{dol}$, are derived from $\beta$-phenylethylamine, the amphetamine precursor. The structures of these drugs have been chemically altered to reduce the potential for abuse. Even though, these anorexiant medications are strictly regulated for short-term therapy. A low-dose anorexiant has been test for long-term therapy. In a phase 3 extension study, a controlled release of phentermine/topiramate (an anticonvulsant) in conjunction with lifestyle modification resulted in up to $10.5 \%$ weightloss for 108 weeks and is well-tolerated. It may provide an effective option for the sustained treatment of obesity [53].

Orlistat works by binding to lipases in the gastrointestinal tract and blocks the digestion of dietary triglycerides. This inhibition of fat digestion reduces micelle formation and, subsequently, reduces the absorption of long-chain fatty acids, cholesterol, and certain fat-soluble vitamins. Excretion of about $30 \%$ of ingested triglycerides, which is near the maximum value, occurs at a dose of $360 \mathrm{mg} /$ day $(120 \mathrm{mg}$ t.i.d with meals). Orlistat has no effect on systemic lipases because less than $1 \%$ of the administered dose is absorbed [54]. Orlistat is notorious for its gastrointestinal side effects, steatorrhea. Serious liver injury events including liver failure in patients using orlistat were collected by FDA's Adverse Event Reporting System. The most commonly reported adverse events of serious liver injury were jaundice, weakness, and abdominal pain. Even though no definite association between liver injury and orlistat has been established, FDA urges both healthcare professionals and consumers to report side effects from the use of orlistat [55].

Metformin has shown its efficacy for weight loss in obese patients with type 2 diabetes [48]. GLP- 1 analogs or GLP1 receptor agonists used in type 2 diabetic patients also demonstrated a weight loss effect [56]. Therefore, they could be potential medications to treat obesity or an approach for weight loss. Theoretically, fat loss could also be achieved through a decrease in the size and number of adipocytes through apoptosis, so that targeting adipocyte apoptosis could be a novel strategy for obesity therapy [57].

5.5. Surgical Therapy. Bariatric surgery is a safe and effective treatment for morbid obesity and related metabolic diseases [58]. It can be categorized as those that primarily cause gastric restriction and those that primarily cause biliopancreatic bypass, subsequently, nutrient maldigestion and malabsorption [50-60]. Perioperative mortality rate after bariatric surgery is less than $0.5 \%$ when the procedure is performed by experienced surgeons in experienced centers [61-63]. Among them, three-fourths of the deaths are due to anastomotic leaks and peritonitis and one-fourth are due to pulmonary embolism. Laparoscopic surgery may be a safer treatment than open surgery. Compared with open 
surgery, laparoscopic surgery is associated with lower risk of wound infection and incisional hernia. As an elective procedure, bariatric surgery should be carefully selected, extensively evaluated, and optimized in order to achieve optimal outcomes. In 1991, guidelines for the surgical treatment of obesity were established by an NIH Consensus Conference, since then these guidelines had hardly been changed $[64,65]$. According to these guidelines, eligible candidates for surgery include patients with a BMI $40 \mathrm{~kg} / \mathrm{m}^{2}$ or more or those with a BMI of 35.0 to $39.9 \mathrm{~kg} / \mathrm{m}^{2}$ and one or more severe medical complications of obesity.

In summary, obesity becomes a world-wide epidemic, the chronic complications result in huge burdens for the patients, family, and society. Although progresses have been made in the management of obesity, an effective safe intervention remains to be developed.

\section{References}

[1] J. Fry and W. Finley, "The prevalence and costs of obesity in the EU," Proceedings of the Nutrition Society, vol. 64, no. 3, pp. 359-362, 2005.

[2] Y. Wang, M. A. Beydoun, L. Liang, B. Caballero, and S. K. Kumanyika, "Will all Americans become overweight or obese? Estimating the progression and cost of the US obesity epidemic," Obesity, vol. 16, no. 10, pp. 2323-2330, 2008.

[3] Z. J. Yang, J. Liu, J. P. Ge et al., "Prevalence of cardiovascular disease risk factor in the Chinese population: the 2007-2008 China National Diabetes and Metabolic Disorders Study," European Heart Journal, vol. 33, no. 2, pp. 213-220, 2012.

[4] Y. Matsuzawa, T. Funahashi, and T. Nakamura, "The concept of metabolic syndrome: contribution of visceral fat accumulation and its molecular mechanism," Journal of Atherosclerosis and Thrombosis, vol. 18, no. 8, pp. 629-639, 2011.

[5] A. C. Frazier-Wood, S. Glasser, W. T. Garvey et al., "A clustering analysis of lipoprotein diameters in the metabolic syndrome," Lipids in Health and Disease, vol. 19, no. 10, article 237, 2011.

[6] M. I. Harris, K. M. Flegal, C. C. Cowie et al., "Prevalence of diabetes, impaired fasting glucose, and impaired glucose tolerance in U.S. adults: the Third National Health and Nutrition Examination Survey, 1988-1994," Diabetes Care, vol. 21, no. 4, pp. 518-524, 1998.

[7] K. M. Flegal and R. P. Troiano, "Changes in the distribution of body mass index of adults and children in the US population," International Journal of Obesity, vol. 24, no. 7, pp. 807-818, 2000.

[8] W. Yang, J. Lu, J. Weng et al., "Prevalence of diabetes among men and women in China," The New England Journal of Medicine, vol. 362, no. 12, pp. 1090-1101, 2010.

[9] W. B. Kannel, N. Brand, J. J. Skinner, T. R. Dawber, and P. M. McNamara, "The relation of adiposity to blood pressure and development of hypertension. The Framingham study," Annals of Internal Medicine, vol. 67, no. 1, pp. 48-59, 1967.

[10] R. Stamler, J. Stamler, W. F. Riedlinger et al., "Weight and blood pressure. Findings in hypertension screening of 1 million Americans," Journal of the American Medical Association, vol. 240, no. 15, pp. 1607-1610, 1978.

[11] J. Shen, A. Goyal, and L. Sperling, "The emerging epidemic of obesity, diabetes, and the metabolic syndrome in china," Cardiology Research and Practice, vol. 2012, Article ID 178675, 5 pages, 2012.
[12] M. Badran and I. Laher, "Obesity in arabic-speaking countries," Journal of Obesity, vol. 2011, Article ID 686430, 9 pages, 2011.

[13] J. E. Manson, W. C. Willett, M. J. Stampfer et al., "Body weight and mortality among women," The New England Journal of Medicine, vol. 333, no. 11, pp. 677-685, 1995.

[14] S. P. Walker, E. B. Rimm, A. Ascherio, I. Kawachi, M. J. Stampfer, and W. C. Willett, "Body size and fat distribution as predictors of stroke among US men," American Journal of Epidemiology, vol. 144, no. 12, pp. 1143-1150, 1996.

[15] B. Mokhlesi, "Obesity hypoventilation syndrome: a state-ofthe-art review," Respiratory Care, vol. 55, no. 10, pp. 13471362, 2010.

[16] K. M. Maclure, K. C. Hayes, G. A. Colditz, M. J. Stampfer, F. E. Speizer, and W. C. Willett, "Weight, diet, and the risk of symptomatic gallstones in middle-aged women," The New England Journal of Medicine, vol. 321, no. 9, pp. 563-569, 1989.

[17] L. Hou, X. O. Shu, Y. T. Gao et al., "Anthropometric measurements, physical activity, and the risk of symptomatic gallstone disease in Chinese women," Annals of Epidemiology, vol. 19, no. 5, pp. 344-350, 2009.

[18] I. R. Wanless and J. S. Lentz, "Fatty liver hepatitis (steatohepatitis) and obesity: an autopsy study with analysis of risk factors," Hepatology, vol. 12, no. 5, pp. 1106-1110, 1990.

[19] J. M. Schattenberg and D. Schuppan, "Nonalcoholic steatohepatitis: the therapeutic challenge of a global epidemic," Current Opinion in Lipidology, vol. 22, pp. 479-488, 2011.

[20] Z. Yang, X. Wang, J. Wen et al., "Prevalence of non-alcoholic fatty liver disease and its relation to hypoadiponectinaemia in the middle-aged and elderly Chinese population," Archives of Medical Science, vol. 7, pp. 665-672, 2011.

[21] E. E. Calle, C. Rodriguez, K. Walker-Thurmond, and M. J. Thun, "Overweight, obesity, and mortality from cancer in a prospectively studied cohort of U.S. Adults," The New England Journal of Medicine, vol. 348, no. 17, pp. 1625-1638, 2003.

[22] A. G. Renehan, M. Tyson, M. Egger, R. F. Heller, and M. Zwahlen, "Body-mass index and incidence of cancer: a systematic review and meta-analysis of prospective observational studies," The Lancet, vol. 371, no. 9612, pp. 569-578, 2008.

[23] B. F. Riecke, R. Christensen, P. Christensen et al., "Comparing two low-energy diets for the treatment of knee osteoarthritis symptoms in obese patients: a pragmatic randomized clinical trial," Osteoarthritis and Cartilage, vol. 18, no. 6, pp. 746-754, 2010.

[24] H. Lundgren, C. Bengtsson, G. Blohme, L. Lapidus, and L. Sjostrom, "Adiposity and adipose tissue distribution in relation to incidence of diabetes in women: results from a prospective population study in Gothenburg, Sweden," International Journal of Obesity, vol. 13, no. 4, pp. 413-423, 1989.

[25] Q. Qiao and R. Nyamdorj, "Is the association of type II diabetes with waist circumference or waist-to-hip ratio stronger than that with body mass index," European Journal of Clinical Nutrition, vol. 64, no. 1, pp. 30-34, 2010.

[26] Z. Pausova, A. Mahboubi, M. Abrahamowicz et al., "Sex differences in the contributions of visceral and total body fat to blood pressure in adolescence," Hypertension, vol. 59, pp. 572-579, 2012.

[27] F. Toss, P. Wiklund, P. W. Franks et al., "Abdominal and gynoid adiposity and the risk of stroke," International Journal of Obesity, vol. 35, no. 11, pp. 1427-1432, 2011.

[28] G. M. Reaven, "Role of insulin resistance in human disease," Diabetes, vol. 37, no. 12, pp. 1595-1607, 1988. 
[29] M. Krssak, K. Falk Petersen, A. Dresner et al., "Intramyocellular lipid concentrations are correlated with insulin sensitivity in humans: a 1H NMR spectroscopy study," Diabetologia, vol. 42, no. 1, pp. 113-116, 1999.

[30] J. B. Meigs, R. B. D’Agostino, P. W. F. Wilson, L. A. Cupples, D. M. Nathan, and D. E. Singer, "Risk variable clustering in the insulin resistance syndrome: the Framingham Offspring Study," Diabetes, vol. 46, no. 10, pp. 1594-1600, 1997.

[31] S. Purkayastha, G. Zhang, and D. Cai, "Uncoupling the mechanisms of obesity and hypertension by targeting hypothalamic IKK- $\beta$ and NF- $\kappa \mathrm{B}$," Nature Medicine, vol. 17, no. 7, pp. 883887,2011

[32] S. Klein, L. E. Burke, G. A. Bray et al., "Clinical implications of obesity with specific focus on cardiovascular disease: a statement for professionals from the American Heart Association Council on Nutrition, Physical Activity, and Metabolism," Circulation, vol. 110, no. 18, pp. 2952-2967, 2004.

[33] G. Oster, D. Thompson, J. Edelsberg, A. P. Bird, and G. A. Colditz, "Lifetime health and economic benefits of weight loss among obese persons," American Journal of Public Health, vol. 89, no. 10, pp. 1536-1542, 1999.

[34] I. D. Caterson, N. Finer, W. Coutinho et al., "Maintained intentional weight loss reduces cardiovascular outcomes: results from the Sibutramine Cardiovascular OUTcomes (SCOUT) trial," Diabetes, Obesity and Metabolism, vol. 14, no. 6, pp. 523-530, 2012.

[35] C. J. Leinum, J. M. Dopp, and B. J. Morgan, "Sleep-disordered breathing and obesity: pathophysiology, complications, and treatment," Nutrition in Clinical Practice, vol. 24, no. 6, pp. 675-687, 2009.

[36] C. Befort, J. R. Klemp, H. L. Austin et al., "Outcomes of a weight loss intervention among rural breast cancer survivors," Breast Cancer Research and Treatment, vol. 132, no. 2, pp. 631639, 2012.

[37] G. Musso, M. Cassader, F. Rosina, and R. Gambino, "Impact of current treatments on liver disease, glucose metabolism and cardiovascular risk innon-alcoholic fatty liver disease (NAFLD): a systematic review and meta-analysis of randomised trials," Diabetologia. In press.

[38] M. D’Hondt, G. Sergeant, B. Deylgat, D. Devriendt, F. Van Rooy, and F. Vansteenkiste, "Prophylactic cholecystectomy, a mandatory step in morbidly obese patients undergoing laparoscopic Roux-en-Y gastric bypass? ” Journal of Gastrointestinal Surgery, vol. 15, no. 9, pp. 1532-1536, 2011.

[39] D. W. Hay and M. C. Carey, "Pathophysiology and pathogenesis of cholesterol gallstone formation," Seminars in Liver Disease, vol. 10, no. 3, pp. 159-170, 1990.

[40] D. Festi, A. Colecchia, M. Orsini et al., "Gallbladder motility and gallstone formation in obese patients following very low calorie diets. Use it (fat) to lose it (well)," International Journal of Obesity, vol. 22, no. 6, pp. 592-600, 1998.

[41] K. Miller, E. Hell, B. Lang, and E. Lengauer, "Gallstone formation prophylaxis after gastric restrictive procedures for weight loss: a randomized double-blind placebo-controlled trial," Annals of Surgery, vol. 238, no. 5, pp. 697-702, 2003.

[42] R. A. Carels, K. M. Young, C. Coit, A. M. Clayton, A. Spencer, and M. Hobbs, "Can following the caloric restriction recommendations from the Dietary Guidelines for Americans help individuals lose weight?" Eating Behaviors, vol. 9, no. 3, pp. 328-335, 2008.

[43] G. Boden, K. Sargrad, C. Homko, M. Mozzoli, and T. P. Stein, "Effect of a low-carbohydrate diet on appetite, blood glucose levels, and insulin resistance in obese patients with type 2 diabetes," Annals of Internal Medicine, vol. 142, no. 6, pp. 403411, 2005.

[44] P. Stiegler and A. Cunliffe, "The role of diet and exercise for the maintenance of fat-free mass and resting metabolic rate during weight loss," Sports Medicine, vol. 36, no. 3, pp. 239-262, 2006.

[45] D. A. Schoeller, K. Shay, and R. F. Kushner, "How much physical activity is needed to minimize weight gain in previously obese women?" American Journal of Clinical Nutrition, vol. 66, no. 3, pp. 551-556, 1997.

[46] J. M. Jakicic, B. H. Marcus, K. I. Gallagher, M. Napolitano, and W. Lang, "Effect of exercise duration and intensity on weight loss in overweight, sedentary women: a randomized trial," Journal of the American Medical Association, vol. 290, no. 10, pp. 1323-1330, 2003.

[47] T. A. Wadden, S. Volger, D. B. Sarwer et al., "A twoyear randomized trial of obesity treatment in primary care practice," The New England Journal of Medicine, vol. 365, no. 21, pp. 1969-1979, 2011.

[48] A. Avenell, J. Broom, T. J. Brown et al., "Systematic review of the long-term effects and economic consequences of treatments for obesity and implications for health improvement," Health Technology Assessment, vol. 8, no. 21, pp. 1-182, 2004.

[49] R. Padwal, S. K. Li, and D. C. Lau, "Long-term pharmacotherapy for obesity and overweight," Cochrane Database of Systematic Reviews (Online), no. 3, article CD004094, 2004.

[50] T. A. Wadden, R. I. Berkowitz, L. G. Womble et al., "Randomized trial of lifestyle modification and pharmacotherapy for obesity," The New England Journal of Medicine, vol. 353, no. 20, pp. 2111-2120, 2005.

[51] M. A. Khan, C. A. Herzog, J. V. S. Peter et al., "The prevalence of cardiac valvular insufficiency assessed by transthoracic echocardiography in obese patients treated with appetitesuppressant drugs," The New England Journal of Medicine, vol. 339, no. 11, pp. 713-718, 1998.

[52] W. N. Kernan, C. M. Viscoli, L. M. Brass et al., "Phenylpropanolamine and the risk of hemorrhagic stroke," The New England Journal of Medicine, vol. 343, no. 25, pp. 1826-1832, 2000.

[53] W. T. Garvey, D. H. Ryan, M. Look et al., "Two-year sustained weight loss and metabolic benefits with controlledrelease phentermine/topiramate in obese and overweight adults (SEQUEL): a randomized, placebo-controlled, phase 3 extension study," American Journal of Clinical Nutrition, vol. 95, no. 2, pp. 297-308, 2012.

[54] J. Zhi, A. T. Melia, C. Funk et al., "Metabolic profiles of minimally absorbed orlistat in obese/overweight volunteers," Journal of Clinical Pharmacology, vol. 36, no. 11, pp. 10061011, 1996.

[55] http://www.fda.gov/Drugs/DrugSafety/PostmarketDrugSafety InformationforPatientsandProviders/DrugSafetyInformation forHeathcareProfessionals/ucm179166.htm.

[56] F. Folli and R. Guardado Mendoza, "Potential use of exenatide for the treatment of obesity," Expert Opinion on Investigational Drugs, vol. 20, pp. 1717-1722, 2011.

[57] Y. Zhang and C. Huang, "Targeting adipocyte apoptosis: a novel strategy for obesity therapy," Biochemical and Biophysical Research Communications, vol. 417, no. 1, pp. 1-4, 2012.

[58] L. Sjöström, M. Peltonen, P. Jacobson et al., "Bariatric surgery and long-term cardiovascular events," JAMA: The Journal of the American Medical Association, vol. 307, no. 1, pp. 56-65, 2012.

[59] B. M. Wolfe and J. M. Morton, "Weighing in on bariatric surgery: procedure use, readmission rates, and mortality," 
Journal of the American Medical Association, vol. 294, no. 15, pp. 1960-1963, 2005.

[60] P. Marceau, F. S. Hould, S. Simard et al., "Biliopancreatic diversion with duodenal switch," World Journal of Surgery, vol. 22, no. 9, pp. 947-954, 1998.

[61] W. J. Pories, M. S. Swanson, K. G. MacDonald et al., "Who would have thought it? An operation proves to be the most effective therapy for adult-onset diabetes mellitus," Annals of Surgery, vol. 222, no. 3, pp. 339-352, 1995.

[62] L. D. MacLean, B. M. Rhode, J. Sampalis et al., "Results of the surgical treatment of obesity," American Journal of Surgery, vol. 165, no. 1, pp. 155-162, 1993.

[63] H. J. Sugerman, J. M. Kellum, K. M. Engle et al., "Gastric bypass for treating severe obesity," American Journal of Clinical Nutrition, vol. 55, no. 2, pp. 560S-566S, 1992.

[64] "Gastrointestinal surgery for severe obesity:National Institutes of Health Consensus Development Conference Statement," American Journal of Clinical Nutrition, vol. 55, no. 2, supplement, pp. 615S-619S, 1992.

[65] J. B. Dixon, P. Zimmet, K. G. Alberti, and F. Rubino, "Bariatric surgery: an IDF statement for obese Type 2 diabetes em obesos," Arquivos Brasileiros de Endocrinologia e Metabologia, vol. 55, no. 6, pp. 367-382, 2011. 


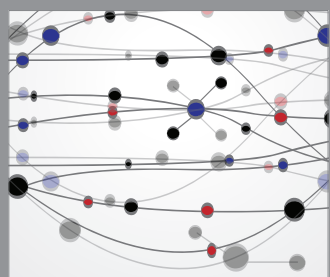

The Scientific World Journal
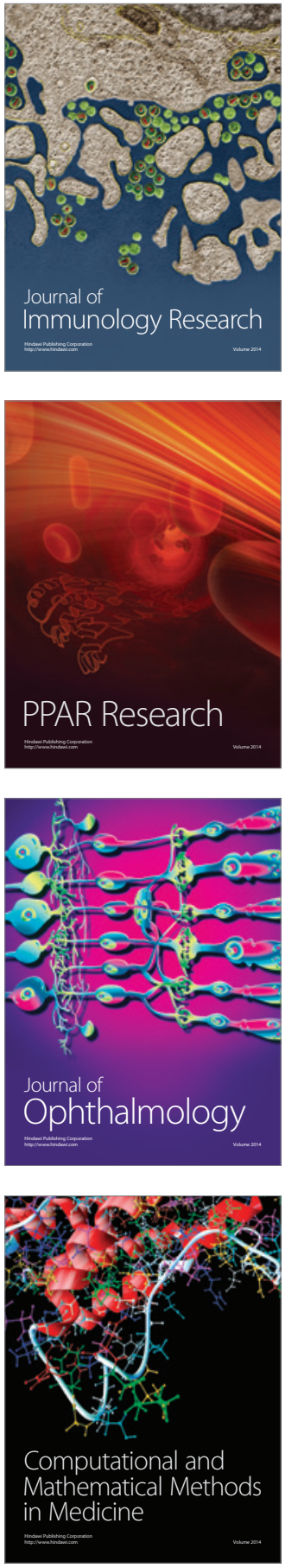

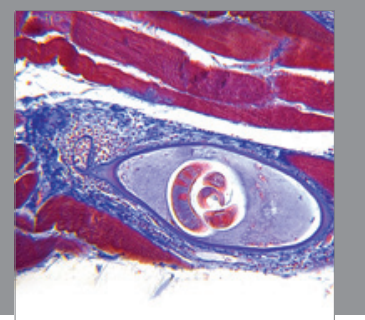

Gastroenterology

Research and Practice
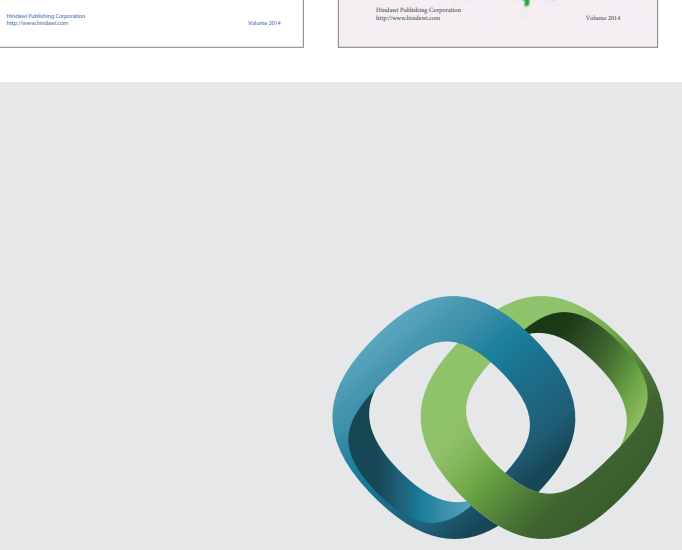

\section{Hindawi}

Submit your manuscripts at

http://www.hindawi.com
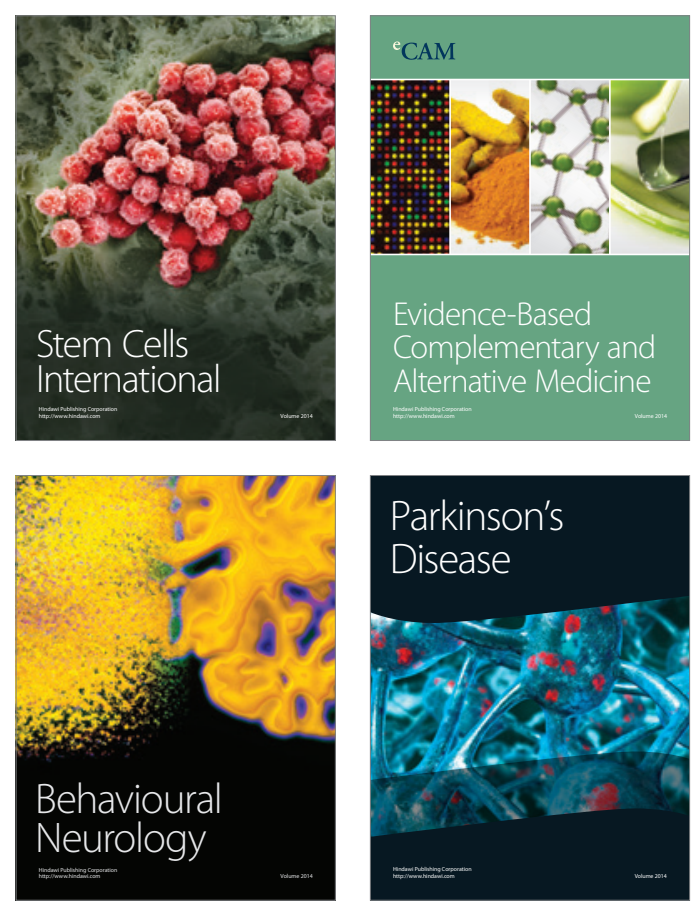

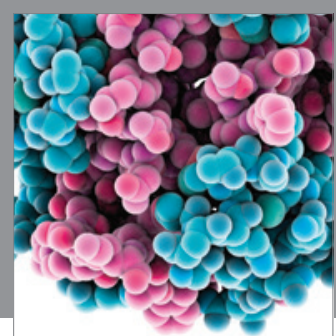

Journal of
Diabetes Research

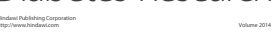

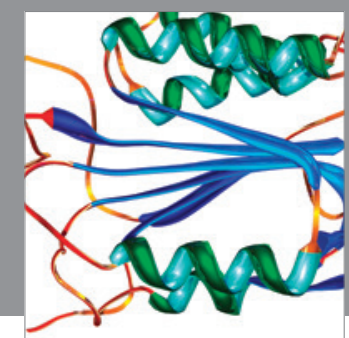

Disease Markers
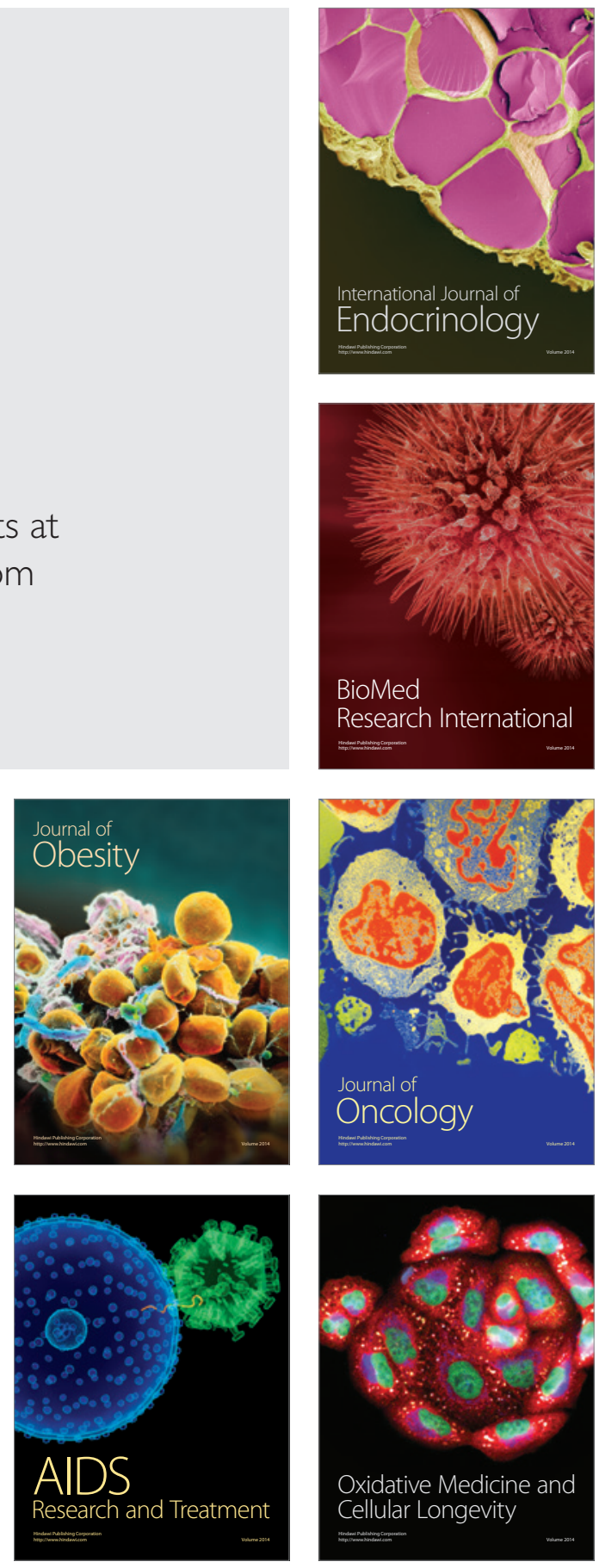